\title{
Statistical analysis of plasmaspheric plumes with Cluster/WHISPER observations
}

\author{
F. Darrouzet ${ }^{1}$, J. De Keyser ${ }^{1}$, P. M. E. Décréau ${ }^{2}$, F. El Lemdani-Mazouz ${ }^{2}$, and X. Vallières ${ }^{2}$ \\ ${ }^{1}$ Belgian Institute for Space Aeronomy (IASB-BIRA), 3 Avenue Circulaire, 1180 Brussels, Belgium \\ ${ }^{2}$ Lab. de Physique et Chimie de l'Environnement (LPCE), 3A Avenue de la Recherche Scientifique, 45071 Orléans, France
}

Received: 22 February 2008 - Revised: 28 April 2008 - Accepted: 9 June 2008 - Published: 6 August 2008

\begin{abstract}
Plasmaspheric plumes have been routinely observed by the four Cluster spacecraft. This paper presents a statistical analysis of plumes observed during five years (from 1 February 2001 to 1 February 2006) based on fourpoint measurements of the plasmasphere (outside 4 Earth radii) as it is sampled by the spacecraft in a narrow local time sector before and after perigee. Plasmaspheric plumes can be identified from electron density profiles derived from the electron plasma frequency determined by the WHISPER wave sounder onboard Cluster. As the WHISPER instrument has a limited frequency range $(2-80 \mathrm{kHz})$ only plumes with densities below $80 \mathrm{~cm}^{-3}$ can be identified in this way. Their occurrence is studied as a function of several geomagnetic indices $\left(K_{p}, a m\right.$ and $\left.D_{s t}\right)$. Their transverse equatorial size, magnetic local time distribution, $L$ position and density variation are discussed. Plasmaspheric plumes are observed mostly for moderate $K_{p}$ and never for small $D_{s t}$. They are found mainly in the afternoon and pre-midnight MLT sectors. Comparisons are also made between the density profiles of the plumes as they are crossed on the in- and outbound legs of the orbit, before and after perigee crossing, respectively.
\end{abstract}

Keywords. Magnetospheric physics (Magnetospheric configuration and dynamics; Plasmasphere; Instruments and techniques)

\section{Introduction}

The plasmasphere is an upward extension of the Earth's ionosphere. It is a torus-like region of dense and cool plasma (density between 10 and $10^{4} \mathrm{~cm}^{-3}$ and temperature of the order of $10^{4} \mathrm{~K}$ ) surrounding the Earth (see the monograph by Lemaire and Gringauz, 1998, and references cited therein). This region extends out to several Earth radii $\left(R_{E}\right)$ to a

Correspondence to: F. Darrouzet

(fabien.darrouzet@oma.be) boundary known as the plasmapause or the plasmasphere boundary layer (Carpenter and Lemaire, 2004). The plasmasphere's configuration and dynamics are highly sensitive to disturbance activity in the solar-terrestrial environment. Previous studies have reported that the location of the plasmapause varies with the level of geomagnetic activity (e.g. Chappell et al., 1970a). During extended quiet periods, the plasmasphere can expand to beyond geosynchronous orbit (e.g. Moldwin et al., 1994), whereas the plasmapause moves earthward, down to $L<3 R_{E}$, during high geomagnetic activity (e.g. Spasojević et al., 2003).

During such active periods after geomagnetic storms or substorms, erosion of the plasmasphere can lead to the formation of density structures called plasmaspheric plumes (e.g. Elphic et al., 1996). Those structures are regions of plasmaspheric plasma that are connected to the main body of the plasmasphere and extend outward into the surrounding more tenuous magnetosphere. Plumes have been predicted on the basis of different theoretical models. When geomagnetic activity increases, the convection electric field becomes stronger as the electric potential across the magnetosphere increases, driven by the interaction between the solar wind and the Earth's magnetosphere. The outer layer of the plasmasphere is stripped away, and the plasmasphere shrinks (Grebowsky, 1970; Chen and Wolf, 1972; Chen and Grebowsky, 1974). This process is known as plasmaspheric erosion. At the same time it produces plasmaspheric plumes which first extend sunward and then rotate around the Earth into the nightside.

Numerical simulations using the Magnetospheric Specification and Forecast Model (MSFM) have clearly reproduced the formation and motion of plasmaspheric plumes (Lambour et al., 1997; Weiss et al., 1997). The Rice University substorm simulation has also shown the formation of plumes near dusk within hours of substorm onset (Spiro et al., 1981). Goldstein et al. (2003a) discuss the importance of the evening convection enhancement associated with

Published by Copernicus Publications on behalf of the European Geosciences Union. 
sub-auroral polarization stream (SAPS) in the formation of plumes. The interchange instability mechanism also predicts the formation of plumes (Lemaire, 1975, 2000; Pierrard and Lemaire, 2004; Pierrard and Cabrera, 2005).

Plasmaspheric plumes have been commonly detected in the past by in-situ satellites, such as OGO 4 and 5 (Chappell et al., 1970b; Taylor et al., 1971), ISEE 1 (Carpenter and Anderson, 1992), CRRES (Moldwin et al., 2004), or geosynchronous satellites (Moldwin et al., 1995; Ober et al., 1997; Borovsky et al., 1998), but also by ground-based instruments (Carpenter et al., 1992, 1993; Su et al., 2001). More recently, plumes have been routinely observed by the Extreme UltraViolet (EUV) imager (Sandel et al., 2000) onboard the IMAGE satellite (Garcia et al., 2003; Sandel et al., 2003; Goldstein et al., 2004; Spasojević et al., 2004; Goldstein and Sandel, 2005; Abe et al., 2006; Kim et al., 2007). Due to the EUV detection limit, plumes with a density lower than $40 \pm 10 \mathrm{~cm}^{-3}$ (Goldstein et al., 2003b) are missed by this imager. Plasmaspheric plumes have also been identified from measurements made onboard the four spacecraft Cluster mission (Darrouzet et al., 2004, 2006a; Décréau et al., 2004, 2005; Dandouras et al., 2005). The combination between insitu instruments and global imaging is very useful (see for example the Cluster-IMAGE study by Darrouzet et al., 2006a). Plasmaspheric plume signatures have also been detected in the ionosphere with measurements of the total electron content measured by global positioning system (GPS) satellites (Foster et al., 2002; Yizengaw et al., 2006).

Before the Cluster and IMAGE missions, the actual topology of plume structures was not understood because of the lack of a global view. Some statistical analysis of plasmaspheric density structures had been done in the past. Chappell (1974) analysed "detached plasma regions" using more than a year of data from the ion mass spectrometer onboard OGO 5. He concluded that those structures are found throughout the dayside magnetosphere, in particular in the afternoon-dusk local time sector. Using the same dataset, but a less restrictive criterion to identify such regions, Kowalkowski and Lemaire (1979) identified other events in the post-midnight and dawn local time sectors. With 10 months of data from the satellite LANL1989-046, Ober et al. (1997) found that these density structures occur at geosynchronous orbit only after extended periods of low magnetospheric activity, identified by the geomagnetic activity index $K_{p}$ and the midnight boundary index. CRRES plasma wave receiver density data have been used by Moldwin et al. (2004) to study the distribution and properties of plasmaspheric plumes from August 1990 to October 1991. They showed that most of the plumes are observed in the noon-to-dusk local time sector after an enhancement of geomagnetic activity identified by the index $K_{p}$ and the disturbance storm-time index $D_{s t}$.

The purpose of this paper is to use a very large database of data from Cluster to make a global statistical analysis of plasmaspheric plumes. After presenting the instrumentation and introducing the key parameters used in the analysis in Sect. 2, the statistical results are discussed in Sect. 3. In Sect. 4 we draw some conclusions.

\section{Plasmaspheric plume seen by Cluster/WHISPER}

\subsection{Data sources}

The Cluster mission consists of four identical spacecraft $(\mathrm{C} 1$, C2, C3 and C4) launched in 2000. They are positioned in a tetrahedral configuration with a separation distance that varies with time, from $100 \mathrm{~km}$ to a few $R_{E}$. The spacecraft fly along similar polar orbits, with a period of approximately $57 \mathrm{~h}$, an apogee of about $19.6 R_{E}$ and a perigee of about $4 R_{E}$ (Escoubet et al., 1997). This allows Cluster to cross the plasmasphere around perigee as the spacecraft fly from the Southern to the Northern Hemisphere. As the Cluster orbit precesses, all magnetic local times (MLT) are covered in the course of the year. The spacecraft only sample the outer plasmasphere due to their high perigee. Each Cluster satellite carries 11 identical instruments. In this study we use data obtained from one of them: the Waves of HIgh frequency and Sounder for Probing Electron density by Relaxation, or WHISPER (Décréau et al., 1997, 2001). This instrument measures the electric field in the frequency range $2-80 \mathrm{kHz}$, with a frequency resolution of $0.163 \mathrm{kHz}$ and a time resolution of $2.1 \mathrm{~s}$ in normal mode. It can unambiguously identify the electron plasma frequency $F_{p e}$, which is related to the electron density $N_{e}$ by

$F_{p e}[\mathrm{kHz}]=9\left(N_{e}\left[\mathrm{~cm}^{-3}\right]\right)^{1 / 2}$.

In active mode, the sounder analyses the pattern of resonances triggered in the medium by a radio pulse, thus allowing the identification of $F_{p e}$ (Trotignon et al., 2001, 2003). In passive mode, the receiver monitors the natural plasma emissions; an independent estimation of $F_{p e}$ can be deduced from local wave cut-off properties (Canu et al., 2001).

\subsection{WHISPER observations of a plasmaspheric plume}

We introduce our statistical analysis of plasmaspheric plumes with an example of a typical plume crossing by the Cluster satellites. This crossing on 18 July 2005, between 13:00 and 20:00 UT, is located around 15:00-16:00 MLT. The maximum value of $K_{p}$ in the previous $24 \mathrm{~h}$ is equal to $5^{+}$. The Cluster spacecraft separation distance is very large $(10000 \mathrm{~km})$. Figure 1 displays frequency-time electric field spectrograms from the four WHISPER instruments for the entire plasmasphere pass. The white line on each spectrogram represents the electron plasma frequency $F_{p e}$ derived from WHISPER. It shows the global profile of the density during this plasmasphere pass. The density variations depend on the existence of both field-aligned and perpendicular density gradients (Darrouzet et al., 2006b; De Keyser et al., 2007). 

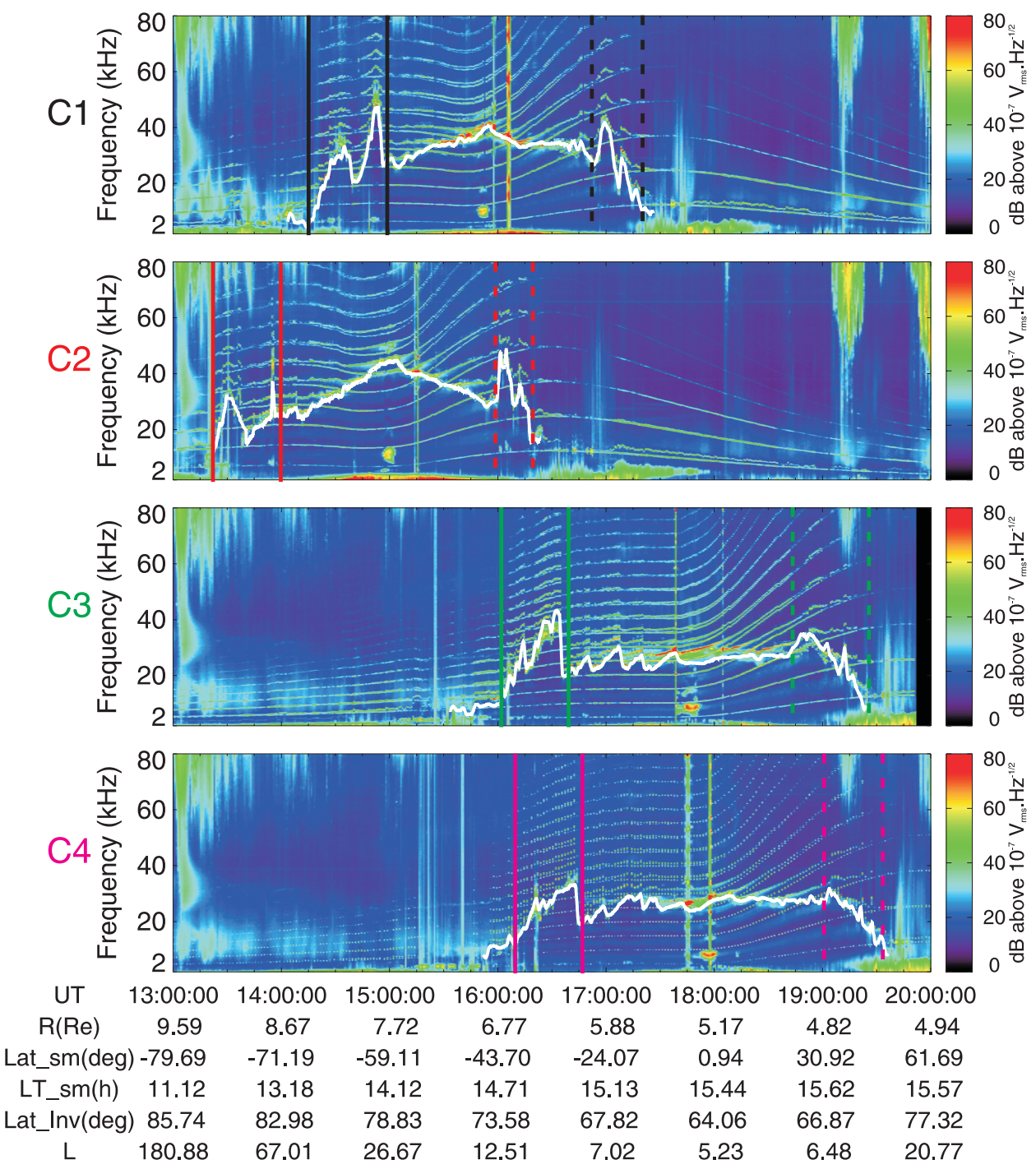

Fig. 1. Frequency-time electric field spectrograms measured on 18 July 2005 by the WHISPER instruments onboard the four Cluster spacecraft. The entire plasmasphere pass is shown, including a plume during the inbound and outbound parts of the pass. The white lines trace the electron plasma frequency $F_{p e}$. The orbital parameters correspond to C4. The colored lines delimit the plume crossings for each satellite, with full lines for the Southern Hemisphere one and dotted lines for the Northern Hemisphere one.

Due to the large spacecraft separation distance, all satellites cross at different times the magnetic equator, which is indicated on WHISPER spectrograms by intense electrostatic emissions (El-Lemdani Mazouz et al., 2006, 2008): C1 crosses the magnetic equator around 16:00 UT, C2 around 15:00 UT, C3 around 17:45 UT and C4 around 18:00 UT. This relative order is similar for the plasmasphere crossing by the four spacecraft: $\mathrm{C} 2$ enters the plasmasphere first at 13:15 UT, then C1 at 14:10 UT, followed by $\mathrm{C} 3$ at 16:00 UT and finally $\mathrm{C} 4$ at 16:15 UT. This explains why $\mathrm{C} 3$ and $\mathrm{C} 4$ display very similar plasmasphere passes, with larger differences as compared to $\mathrm{C} 1$ and $\mathrm{C} 2$. The differences between the satellites are due to space variability of the plasmasphere, but also time variability. The spectrograms exhibit plume crossings during the inbound pass in the Southern Hemisphere (SH), and also during the outbound pass in the Northern Hemisphere (NH), with differences in the density profiles between the four spacecraft. For example, $\mathrm{C} 1$ and $\mathrm{C} 2$ show two peaks across the inbound plume, structures not seen by $\mathrm{C} 4$, which crosses the plasmasphere about $2 \mathrm{~h}$ later.

We characterize each plume crossing by means of several parameters. A plume is identified as a significant and localized density increase $\left(10 \mathrm{~cm}^{-3}\right.$ minimum) followed by a density decrease from the background value, adjacent to the 


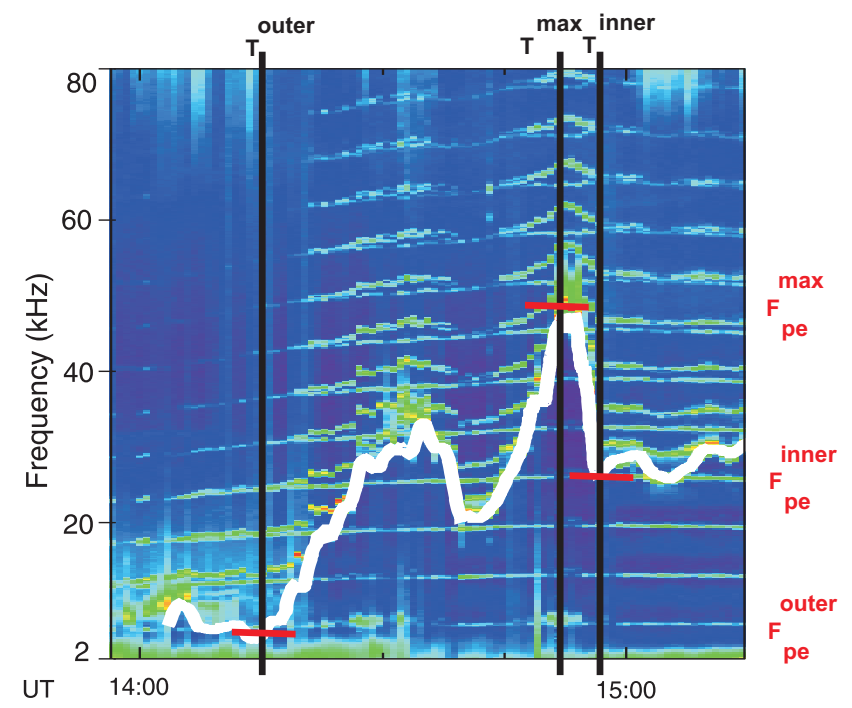

Fig. 2. Frequency-time spectrogram measured on 18 July 2005 by the WHISPER instrument onboard $\mathrm{C} 1$. The inbound plume crossing is shown. Time and plasma frequency of the outer and inner boundaries of the plume are shown, as well as the time and plasma frequency of the maximum recorded during the plume crossing.

main plasmasphere crossing. The $L$-width of the structure should be large enough to be considered as a plume, $0.2 R_{E}$ minimum. Figure 2 is a zoom on the plume crossed by $\mathrm{C} 1$ during the inbound plasmasphere pass on 18 July 2005. We define the times of the outer and inner boundaries of the plume, $T^{\text {outer }}$ and $T^{\text {inner }}$ respectively, and also the time $T^{\text {max }}$ of the electron plasma frequency maximum. We also record the frequency value at each of those times: $F_{p e}^{\text {outer }}, F_{p e}^{\text {inner }}$ and $F_{p e}^{\max }$. A double plume, as in the present case, is considered as a single structure, and the maximum plasma frequency is then the maximum of both sub-plumes. At each of the three times defined for each plume crossing, we determine all the parameters needed for the statisical study: the orbital parameters $L$ and MLT, the geomagnetic indices $K_{p}, a m$ and $D_{s t}$, and the values of the electron density $N_{e}$ derived from the corresponding $F_{p e}$ (by the use of Eq. 1). Those parameters characterize the plasmaspheric plumes in terms of their occurrence as a function of geomagnetic activity, but also in term of their properties and geometry.

Since Cluster's plasmasphere passes occur in a fairly narrow local time sector, only the "tips" of plumes can be detected. We can identify a plume when a satellite successively traverses a density peak, a density decrease and the main plasmasphere, as shown by the green curve on Fig. 3. For this sketch, we have chosen the common orientation of a plume: a plume observed from above in the equatorial plane in a corotating frame has a spiral shape oriented clockwise. If the satellite crosses the "foot" of the plume, as shown for the inbound pass on Fig. 3 with the blue curve, it is impossible to distinguish between the plume and the main plasma-sphere.

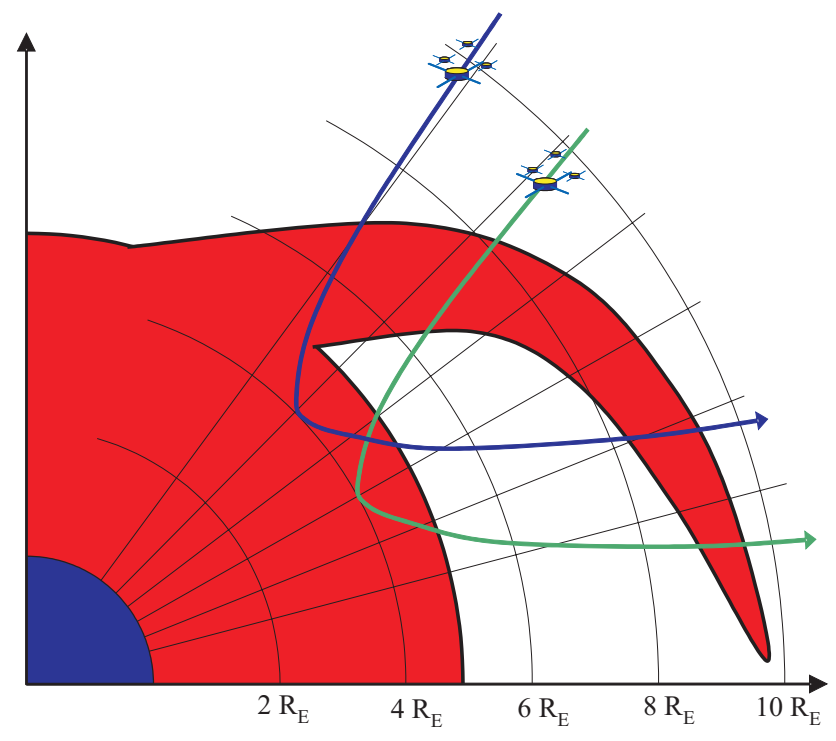

Fig. 3. Sketch of the crossing of a plasmaspheric plume by a Cluster satellite, projected onto the equatorial plane in a co-rotating frame. The green and blue lines represent two different trajectories and the red shape sketches the plasmasphere with a plume.

The characteristics of the plume crossings on 18 July 2005 are summarized in Table 1, for each inbound and outbound crossing by the four Cluster satellites. We can note on the spectrograms of Fig. 1 that the maximum plasma frequency in the plumes is different for each spacecraft. For the outbound plume of $\mathrm{C} 2 F_{p e}^{\max }$ is around $50 \mathrm{kHz}$ (or $N_{e}$ around $\left.31 \mathrm{~cm}^{-3}\right)$, whereas it is $42 \mathrm{kHz}\left(22 \mathrm{~cm}^{-3}\right)$ for $\mathrm{C} 1$ and $32 \mathrm{kHz}$ $\left(13 \mathrm{~cm}^{-3}\right)$ for $\mathrm{C} 3$ and $\mathrm{C} 4$. The inner part of this plasmasphere pass also differs between the four satellites, with a "plateau" structure for $\mathrm{C} 3$ and $\mathrm{C} 4\left(F_{p e}\right.$ between 20 and $30 \mathrm{kHz}$, or $N_{e}$ between 5 and $11 \mathrm{~cm}^{-3}$ ), whereas $F_{p e}$ has a maximum value at the magnetic equator around $42 \mathrm{kHz}\left(22 \mathrm{~cm}^{-3}\right)$ for $\mathrm{C} 2$ and $40 \mathrm{kHz}\left(20 \mathrm{~cm}^{-3}\right)$ for $\mathrm{C} 1$.

In order to understand such differences, we need to analyse the trajectories of the four spacecraft. Figure 4 shows the electron density plotted along the trajectories of $\mathrm{C} 1, \mathrm{C} 2$ and $\mathrm{C} 3$ in solar magnetic (SM) coordinates (C4 nearly coincides with $\mathrm{C} 3$ during this time interval and is therefore not shown). The dashed lines are dipole magnetic field lines. The closer the satellites are to the Earth, the higher the density is: C2 records higher density than $\mathrm{C} 1$ than $\mathrm{C} 3$, as seen on the spectrograms. The plume is clearly divided into 2 sub-plumes during the $\mathrm{SH}$ pass of $\mathrm{C} 1$ and $\mathrm{C} 2$. The same feature is not as clearly observed on $\mathrm{C} 3$. This can be due to the time difference between the crossings, and also to the differences in local time. Note that the plume crossings in both hemispheres map essentially onto the same magnetic field line (given that the dipole approximation is rather rough). 
Table 1. Characteristics of the plume crossings by Cluster on 18 July 2005. The times of the outer and inner boundaries of each plume crossing are given, as well as the time of the maximum electron plasma frequency value. The plasma frequencies are given for each of those times. The $L$ and MLT for the inner and outer boundaries are also given.

\begin{tabular}{l|ccc|ccc|rc|rc}
\hline & \multicolumn{3}{|c}{$T(\mathrm{UT})$} & \multicolumn{3}{c}{$F_{p e}(\mathrm{kHz})$} & \multicolumn{2}{c}{$L\left(R_{E}\right)$} & \multicolumn{2}{c}{ MLT } \\
& $T^{\text {outer }}$ & $T^{\text {max }}$ & $T^{\text {inner }}$ & $F_{p e}^{\text {outer }}$ & $F_{p e}^{\max }$ & $F_{p e}^{\text {inner }}$ & $L^{\text {outer }}$ & $L^{\text {inner }}$ & $M L T^{\text {outer }}$ & $M L T^{\text {inner }}$ \\
\hline C1 IN & $14: 17$ & $14: 54$ & $14: 56$ & 10 & 49 & 28 & 10.2 & 7.0 & $14: 58$ & $15: 12$ \\
C1 OUT & $17: 14$ & $16: 58$ & $16: 54$ & 14 & 42 & 27 & 9.7 & 7.1 & $15: 58$ & $15: 50$ \\
C2 IN & $13: 24$ & $13: 54$ & $13: 56$ & 10 & 40 & 31 & 10.9 & 7.5 & $14: 22$ & $14: 38$ \\
C2 OUT & $16: 17$ & $16: 01$ & $15: 59$ & 15 & 47 & 27 & 9.2 & 6.9 & $15: 48$ & $15: 36$ \\
C3 IN & $16: 04$ & $16: 32$ & $16: 36$ & 13 & 42 & 20 & 10.8 & 8.2 & $14: 48$ & $15: 02$ \\
C3 OUT & $19: 22$ & $18: 53$ & $18: 48$ & 13 & 32 & 24 & 10.1 & 8.7 & $15: 39$ & $15: 37$ \\
C4 IN & $16: 10$ & $16: 43$ & $16: 44$ & 13 & 35 & 19 & 11.0 & 8.3 & $14: 48$ & $15: 02$ \\
C4 OUT & $19: 29$ & $19: 05$ & $19: 02$ & 12 & 31 & 26 & 9.8 & 8.4 & $15: 38$ & $15: 37$ \\
\hline
\end{tabular}

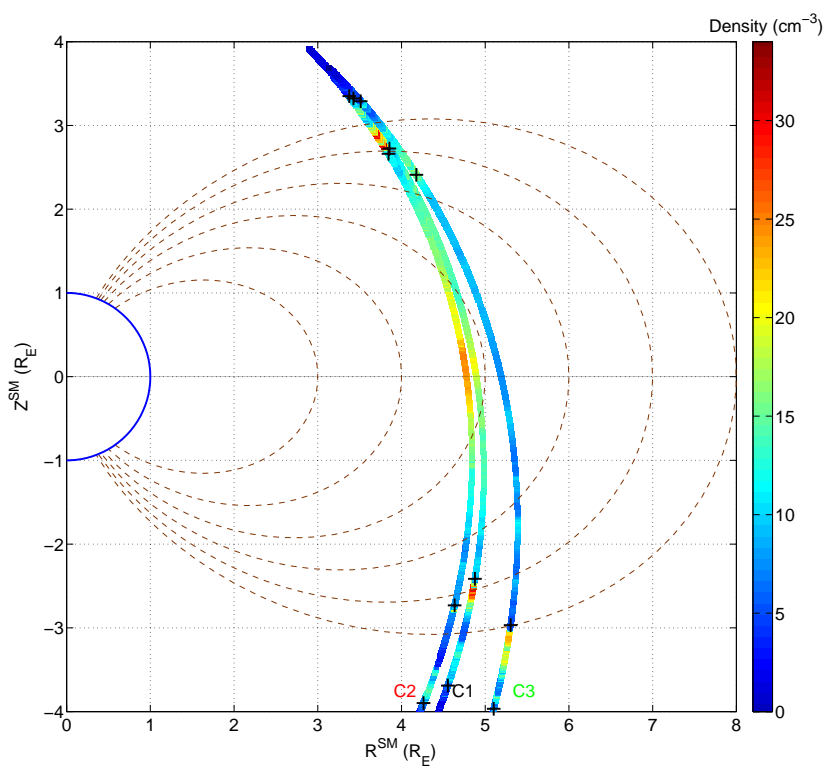

Fig. 4. Electron density plotted along the trajectories of $\mathrm{C} 1, \mathrm{C} 2$ and $\mathrm{C} 3$ projected in the $R-Z$ solar magnetic (SM) coordinate system during the plasmasphere pass on 18 July 2005 . The density is plotted with the color scale on the right. The brown lines are dipole magnetic field lines for $L$ between 3 and $8 R_{E}$, plotted here to guide the eye. The crosses show the times of the plume crossings $T^{\text {inner }}$ and $T^{\text {outer }}$ indicated in Table 1.

More information can be deduced if we project the Cluster trajectories along the magnetic field lines onto the equatorial plane. We use here a model that combines the internal magnetic field model IGRF2000 and the external magnetic field model Tsyganenko-96, which depends on the solar wind pressure, the $D_{s t}$ index and the interplanetary magnetic field (IMF) $Y$ and $Z$ components (Tsyganenko and Stern, 1996). These models are computed with the UNILIB library (Library of routines for magnetospheric applications: http://www.oma.be/NEEDLE/unilib.php/). As the separation

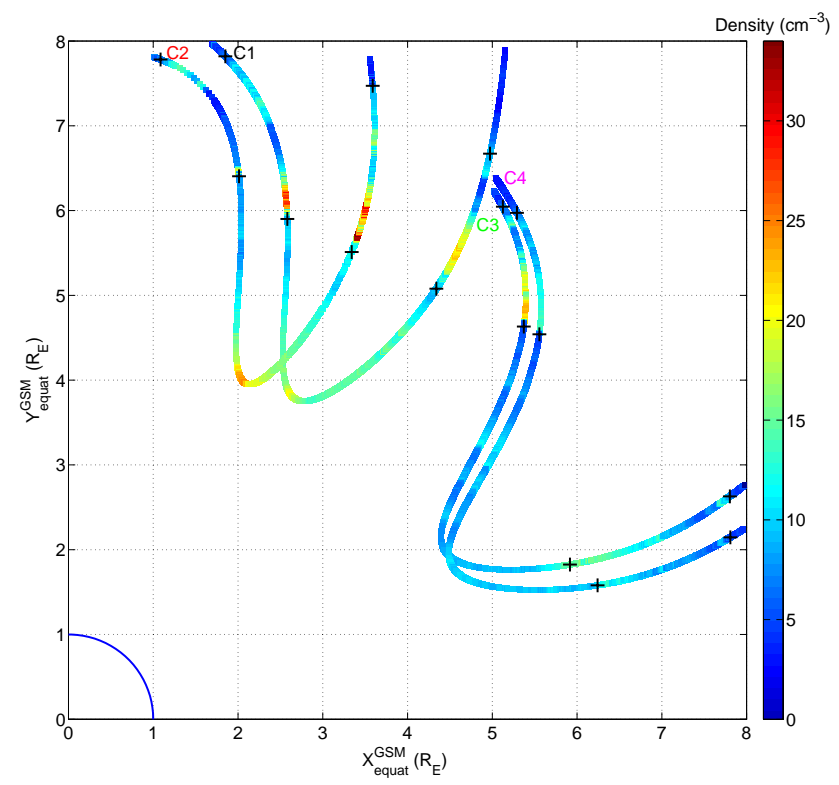

Fig. 5. Electron density plotted along the trajectories of $\mathrm{C} 1, \mathrm{C} 2$, $\mathrm{C} 3$ and $\mathrm{C} 4$ projected along the magnetic field lines onto the equatorial plane in a co-rotating geocentric solar magnetospheric (GSM) frame of reference (chosen such that C4 was at 15:30 MLT at 18:00 UT), during the plasmasphere pass on 18 July 2005. The density is plotted with the color scale on the right. The crosses show the times of the plume crossings $T^{\text {inner }}$ and $T^{\text {outer }}$ indicated in Table 1.

distance between the satellites is quite large, and in order to be able to compare the four trajectories and the eight crossings, we assume that the plasmasphere and its sub-structures are in co-rotation with the Earth. Figure 5 presents such a projection for $\mathrm{C} 1, \mathrm{C} 2, \mathrm{C} 3$ and $\mathrm{C} 4$ in a co-rotating geocentric solar magnetospheric (GSM) frame of reference (chosen such that C4 was at 15:30 MLT at 18:00 UT). The plasmasphere passes start at the label of each satellite (on the left), and end on the right side. The plasmapause is clearly seen 


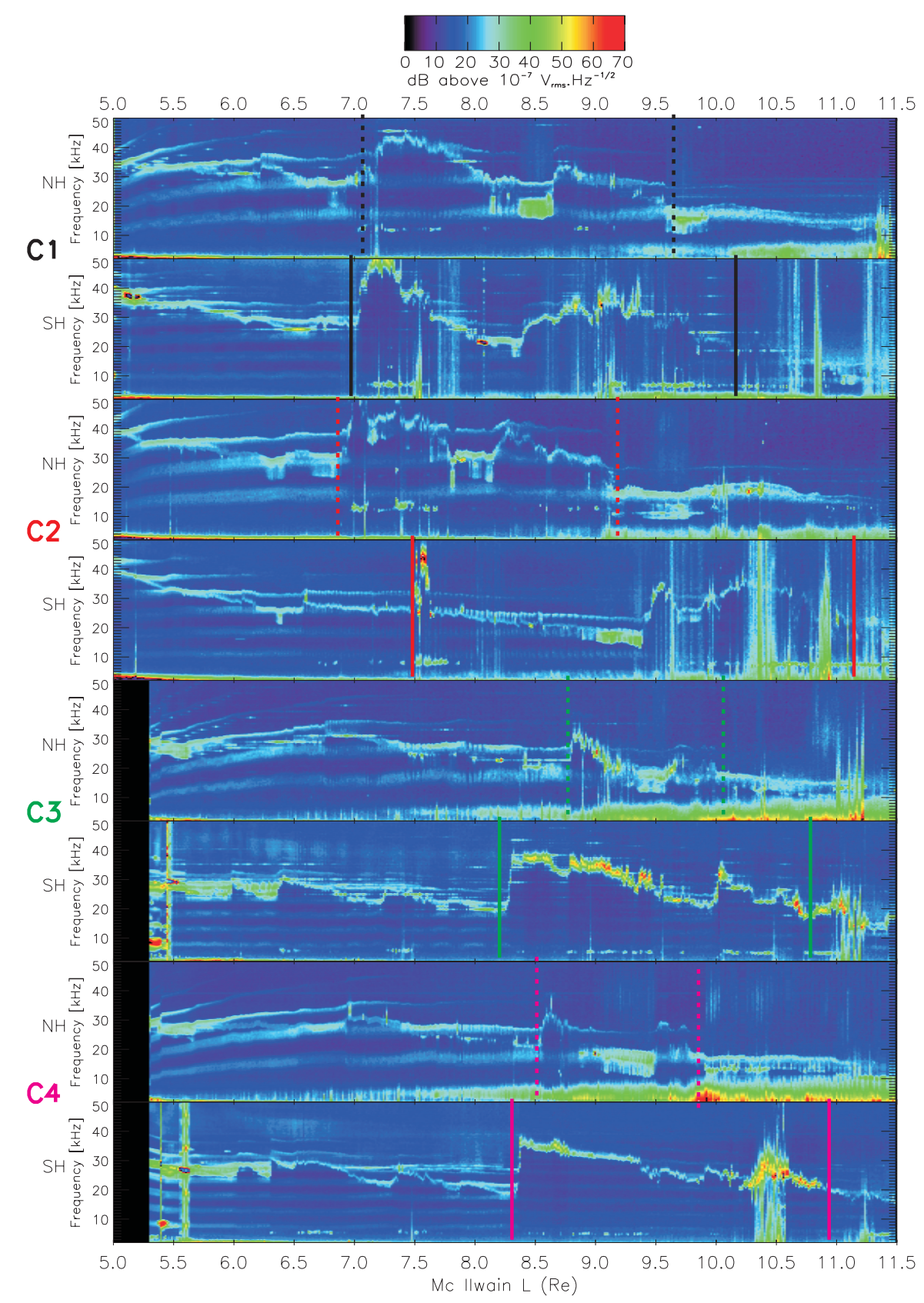

Fig. 6. Electric field spectrograms measured on 18 July 2005 by the WHISPER instruments as a function of the McIlwain $L$ parameter onboard the four Cluster spacecraft. The figure is divided into a Northern Hemisphere (NH) panel and a Southern Hemisphere (SH) panel for each satellite. Colored lines delimit the plume crossings for each satellite, with full lines for SH and dotted lines for NH.

on the trajectories of $\mathrm{C} 1$ and $\mathrm{C} 2$ at a radial distance of $5 R_{E}$, where the color coded density changes from green to yellow. A clear plasmapause is not crossed by $\mathrm{C} 3$ and $\mathrm{C} 4$, which do not show an enhanced density around the actual perigee crossing. This could be because the plasmasphere could be located closer to Earth at this different local time position, and at this later point in time. The plume crossings are clearly observed on all four satellites and indicated on the figure with crosses, which represent the crossing times deduced from the spectrograms. We can see that the inbound crossings by the four satellites, and the outbound crossings by $\mathrm{C} 1$ and $\mathrm{C} 2$, are clearly crossings of the same plume, which co-rotates as 
time elapses between successive spacecraft crossings. The outbound crossing by $\mathrm{C} 3$ and $\mathrm{C} 4$ (bottom right of Fig. 5) is probably another density structure.

Figure 6 gives the electric field spectrograms from WHISPER as a function of the McIlwain $L$ parameter (Mcllwain, 1961) for each inbound and outbound plasmasphere pass. This figure is divided into 4 pairs of panels, one pair for each satellite, with each time first the NH pass and then the SH pass. $L$ varies for this event between 4.5 to $12.5 R_{E}$, and the data are plotted with a frequency range $2-50 \mathrm{kHz}$ in order to zoom on the plume structures. There are lots of differences in terms of the $L$ position of the plume between the four spacecraft. This is logical, as some of the satellites cross the density structure a few hours after the first one; during this time period, the plume has rotated around the Earth, but has also moved to higher $L$ values. The inner boundary of the $\mathrm{SH}$ plume is seen around $L=7.0 R_{E}$ by $\mathrm{C} 1$, whereas this boundary is crossed $2 \mathrm{~h}$ later by $\mathrm{C} 3$ and $\mathrm{C} 4$ around $L=8.3 R_{E}$. Knowing that the MLT position of the plume crossing is quite similar for those 3 satellites, we can then calculate an average radial velocity of the plume at fixed MLT of the order of $1.2 \mathrm{~km} \mathrm{~s}^{-1}$, which is consistent with the results by Darrouzet et al. (2006a). Figure 6 shows also that the plume is crossed by $\mathrm{C} 1$ around similar $L$ values in both hemispheres, but with small differences in the small-scale density structures. Note that the SH inbound crossing of the plume by $\mathrm{C} 2\left(4^{\text {th }}\right.$ panel of Fig. 6 from the top) is at much higher $L$ value than the $\mathrm{NH}$ crossing by the same satellite $\left(3^{\text {rd }}\right.$ panel of Fig. 6 from the top) and than both crossings from $\mathrm{C} 1$, whereas the time delay between $\mathrm{C} 1$ and $\mathrm{C} 2$ is not very important. As seen in Fig. 5, the SH trajectory of $\mathrm{C} 2$ is quite different from that of C1. Moreover, the MLT sector of the SH crossing by $\mathrm{C} 2$ is also quite different from $\mathrm{C} 1$ (around 14:30 MLT for $\mathrm{C} 2$ and around 15:05 MLT for C1). Those orbit differences clearly explain why the $L$ position of the outbound plume crossing is larger for $\mathrm{C} 2$ than for $\mathrm{C} 1$.

Concerning the $L$-widths of the plumes $\Delta L$, there are many differences between the spacecraft, and also between the inbound and outbound crossings for some satellites. For $\mathrm{C} 1, \Delta L=3.2 R_{E}$ during $\mathrm{SH}$, and $2.6 R_{E}$ during $\mathrm{NH}$. This means that the outbound crossing, taking place a few hours after the inbound one, detects a narrower plume. We obtain a similar trend for the other satellites. Another characteristic of those plume crossings is the evolution of the maximum value of the electron plasma frequency and the electron density inside the plume. For $\mathrm{C} 1, N_{e}^{\max }=30 \mathrm{~cm}^{-3}$ in $\mathrm{SH}$, whereas $N_{e}^{\max }=22 \mathrm{~cm}^{-3}$ in NH. For C $3, N_{e}^{\max }$ varies from 22 to $12 \mathrm{~cm}^{-3}$ from $\mathrm{SH}$ to $\mathrm{NH}$. Except for $\mathrm{C} 2$, the maximum electron density inside the plume is always higher in the inbound pass than in the outbound one. All those characteristics can be explained by the fact that during the plasmasphere pass, the plume has rotated so that the outbound crossings occur closer to the tip of the plume, which is narrower and has lower density (see sketch of a typical plume crossing in Fig. 3). Note that, contrary to plasmasphere passes with a small spacecraft separation distance, it is not possible here to analyse the plume crossings by the four spacecraft with multipoint analysis tools such as the spatial gradient (Darrouzet et al., 2006a).

\section{Statistical analysis}

After having introduced the key parameters useful for our study in a typical plasmaspheric plume crossing, we now present a statistical analysis of plumes with five years of Cluster data.

\subsection{Data selection}

This statistical study is based on data from the four Cluster spacecraft during exactly five years, from 1 February 2001 to 1 February 2006, to ensure equal coverage of all MLT sectors. Note that our set of events is not a completely random sample, as some events are seen by all four satellites, especially in the case of small spacecraft separation distance. Note also that due to the polar orbit of Cluster, the spacecraft usually cross only the tips of the plumes. During the first year and a half, the data of some plasmasphere passes were not available (no 100\% coverage), but after July 2002, the mission started to have full data coverage of the orbit. With a period of $57 \mathrm{~h}$ and four spacecraft making inbound and outbound passes, there are 6150 plasmasphere passes. We have in fact 5222 passes with data available, which corresponds to $85 \%$. Of these missing $15 \%$, around $50 \%$ comes from incomplete data coverage (before July 2002), around $10 \%$ from data not available during satellite manoeuvres, and around $40 \%$ from WHISPER instrument not working properly on one or several satellites. Figure 7 shows the probability of having a plasmasphere pass in each $L-$ MLT bin, based on the 5222 plasmasphere passes in our study. We have used orbital parameters ( $L$, MLT) with a time resolution of $1 \mathrm{~min}$. There is a global coverage of all MLT sectors and of all $L$ values above $4 R_{E}$ (perigee of Cluster).

We use WHISPER time-frequency electric field spectrograms as well as $L$-frequency spectrograms to select the intervals with a plume crossing. When needed, in case of very complicated events, we check data from other instruments, for example the ion density from the Cluster Ion Spectrometry experiment, CIS (Rème et al., 2001), and also EUV images (Sandel et al., 2000) onboard the IMAGE satellite (Burch, 2000). Following the plume identification introduced in Sect. 2.2, the plasmasphere passes are classified into three types: with plumes, without plumes, and questionable conclusion. This last type corresponds to very complicated events (like crossings where we suspect strong time variability). We have 34 cases of this type, which is only around $1 \%$ of the total number of passes, so that this does not distort our statistics. Note that clear double plumes are considered as a 


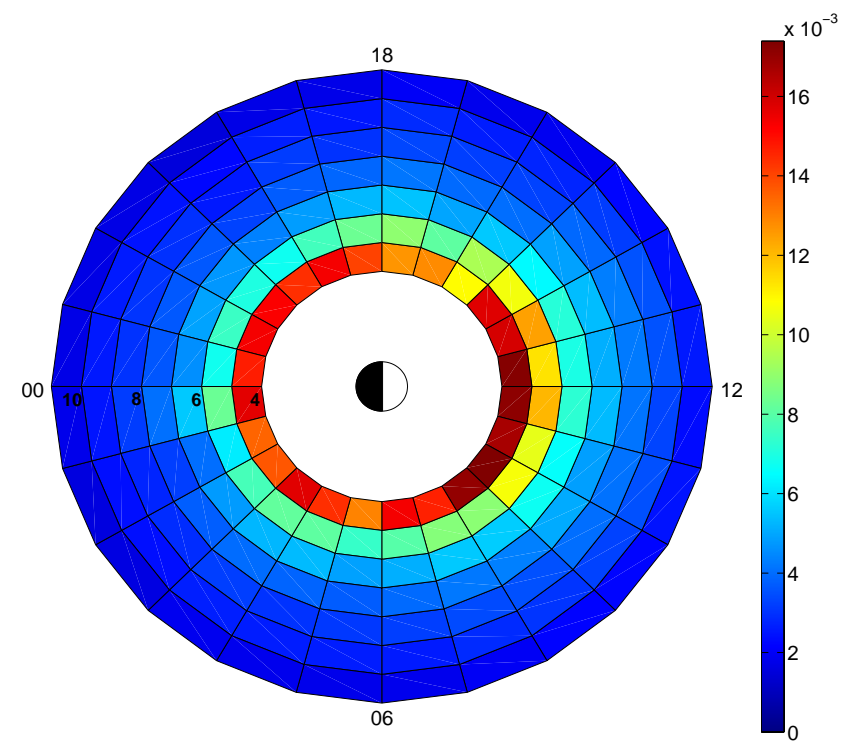

Fig. 7. Probability of having plasmasphere observations in each $L-$ MLT bin, based on the 5222 plasmasphere passes in our study. $L$ varies between 4 and $11 R_{E}$.

single structure and are processed similar to the first type of crossings.

We obtain 782 plume crossings, which correspond to $15 \%$ of the plasmasphere passes with data (5222 passes). This is smaller as compared to other studies: Moldwin et al. (2004) found a proportion of $30 \%$ of clear plasmasphere passes with plume structures. There are three possible explanations. First, the frequency range of the WHISPER instrument has an upper limit of $80 \mathrm{kHz}$, which corresponds roughly to $80 \mathrm{~cm}^{-3}$, which is a quite low value for density inside the plasmasphere. Therefore, if a plasmasphere has a plume with higher density value, the WHISPER instrument can not identify it clearly. Moreover, if the density between the plume and the main plasmasphere is above $80 \mathrm{~cm}^{-3}$, it will not be possible to distinguish the plume. Second, due to the high perigee of Cluster, the satellites do not enter deeply into the plasmasphere during high geomagnetic activity time periods, so that they could miss an eventual plume. Third, due to the polar orbit of Cluster, usually only the tips of plumes can be identified. The probabilities of finding a plume at a given $L$-MLT location (normalized by the spacecraft coverage) are presented in Fig. 8. It shows clearly that we observe most of the plumes in the afternoon and pre-midnight MLT sectors. There are no data below the perigee of Cluster $\left(L<4 R_{E}\right)$. Some plumes are observed at high $L$, especially in the afternoon MLT sector. Magnetic mapping may be a little questionable at high $L$, especially on the dayside, but that does not affect the conclusions. There are very few plumes in the post-midnight and morning MLT sectors. If there is a plume at $L=6 R_{E}$ and 21:00 MLT, the foot of the

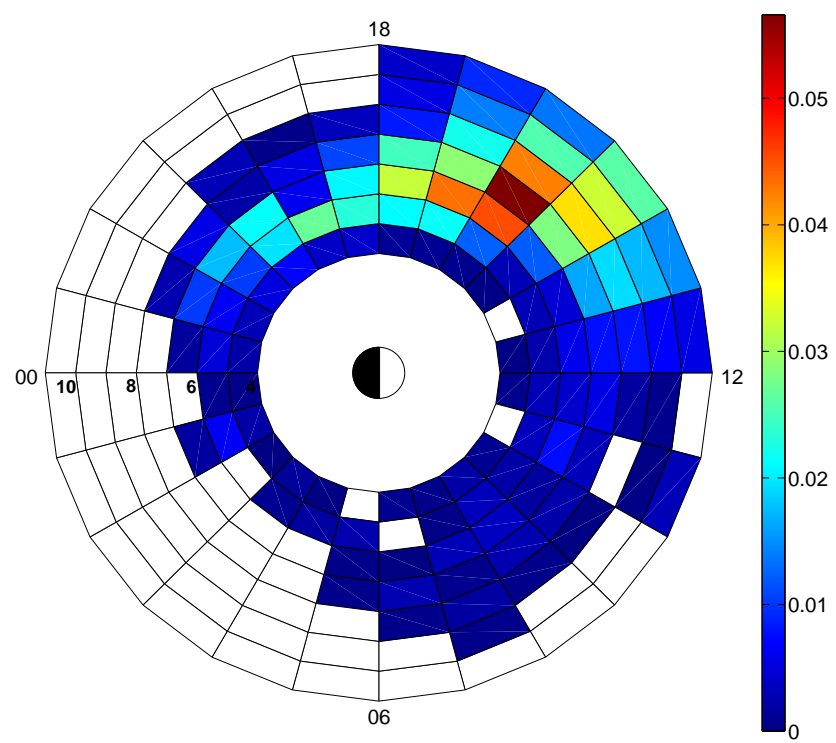

Fig. 8. Probability of being inside a plume structure for each $L-$ MLT bin, normalized by the distribution of all the trajectories. $L$ varies between 4 and $11 R_{E}$.

plume should be at lower $L$ in the post-midnight sector, as shown in a study using Cluster and IMAGE by Darrouzet et al. (2006a), but Cluster will not be able to detect it, as discussed earlier.

\subsection{Geomagnetic indices: $K_{p}, a m, D_{s t}$}

As in most previous studies of plasmaspheric plumes, we use the $K_{p}$ index to study their occurrence as a function of geomagnetic activity. The plasmapause is assumed to be formed in the midnight sector following the theory that interchange motion is driven unstable along the Roche Limit surface (Lemaire, 1975, 2001). To try to compensate for plasmasphere rotation, a time delayed $K_{p}$ value is chosen that corresponds to the time elapsed since the observed structure passed the midnight meridian (assuming full co-rotation). The instantaneous value of $K_{p}$ is used when the spacecraft are between 21:00 and 03:00 MLT, the maximum value of $K_{p}$ in the preceding $6 \mathrm{~h}$ is used between 03:00 and 09:00 MLT, the maximum value in the previous $12 \mathrm{~h}$ between 09:00 and 15:00 MLT, and the maximum value in the previous $18 \mathrm{~h}$ between 15:00 and 21:00 MLT. In the remainder of the paper, $K_{p}$ will denote this time delayed value. We use also the $\mathrm{am}$ index, which is calculated as the $K_{p}$ index but with a larger network (especially with ground-based stations at higher latitudes), and also the $D_{s t}$ index. The am indices are chosen following the same outline as $K_{p}$, and the $D_{s t}$ values used in the statistical study are the minimum values in the previous $24 \mathrm{~h}$.

Figure 9a-c presents, respectively, the distributions of the $K_{p}, a m$ and $D_{s t}$ values for all the plasmasphere passes 

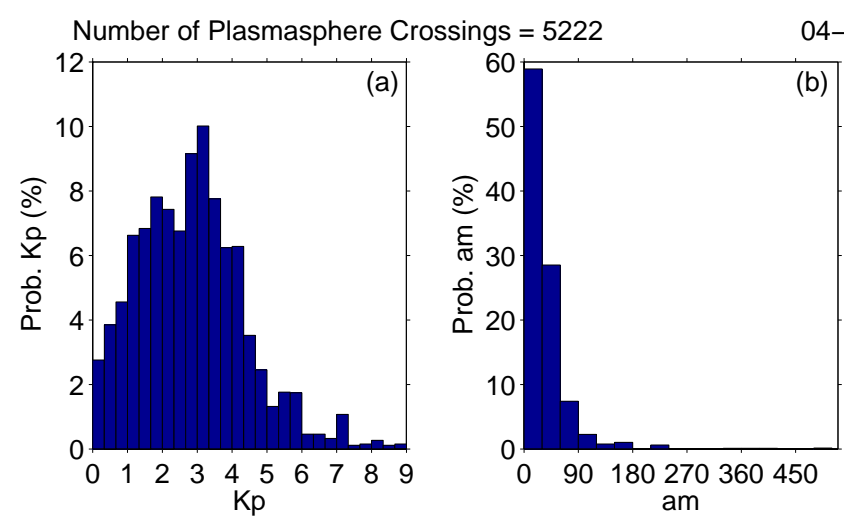

04-Feb-2001 < Day < 29-Jan-2006
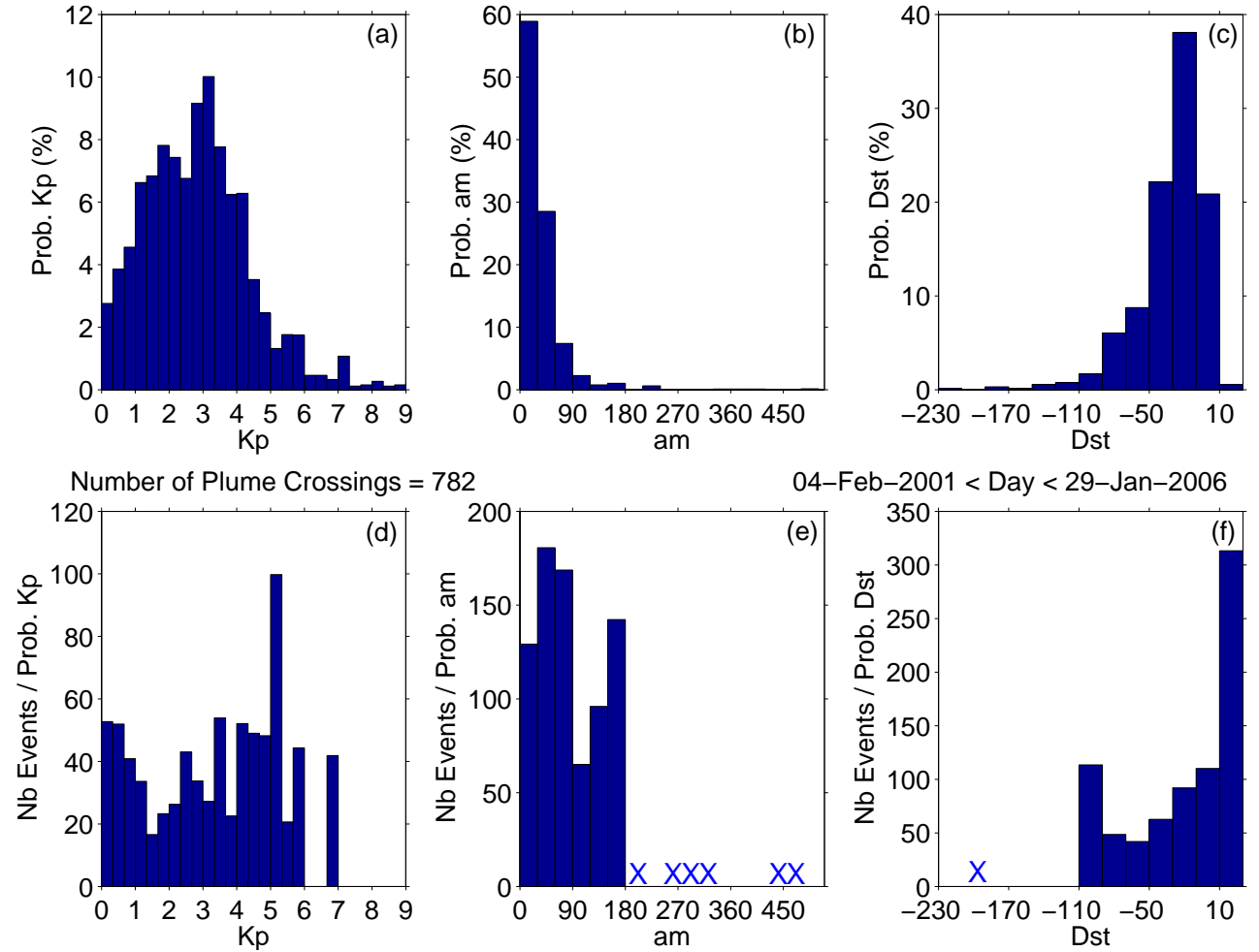

Fig. 9. Occurrence of plasmasphere passes (top panels) and plasmaspheric plumes (bottom panels) as a function of the indices $K_{p}, a m$ and $D_{s t}$ during the five years of Cluster data analysed. (a) Distribution of the $K_{p}$ values for the plasmasphere passes. (b) Distribution of the am values for the plasmasphere passes. (c) Distribution of the $D_{s t}$ values for the plasmasphere passes. (d) $K_{p}$ distribution of the plumes, weighted by the $K_{p}$ occurrence probability. (e) am distribution of the plumes, weighted by the am occurrence probability. (f) $D_{s t}$ distribution of the plumes, weighted by the $D_{s t}$ occurrence probability. A blue cross means that there are no plasmasphere passes with such values.

analysed in this study. It shows that the dataset contains passes for almost all $K_{p}$ values and a large range of $a m$ (up to 510 ) and $D_{s t}$ (down to -230 ), but mostly for low to moderate geomagnetic activity. There are only a few plasmasphere passes with high $K_{p}$ and $a m$, and very low $D_{s t}$, mainly because the plasmasphere is closer to the Earth in this case, and therefore not crossed by the Cluster satellites. Figure $9 \mathrm{~d}-$ f shows the $K_{p}$, am and $D_{s t}$ distributions of the plumes, weighted by the occurrence probabilities of those parameters. No plumes are observed for the highest $K_{p}(>7)$, the highest $a m(>180)$ and the lowest $D_{s t}(<-110)$. In this case, the plasmasphere is moving closer to the Earth, sometimes below the perigee of Cluster $\left(4 R_{E}\right)$, and if there would be a plume, it could stand below the Cluster orbit. That could explain why we do not observe any plasmaspheric plumes in case of high geomagnetic activity. We note that there are more events for moderate activity $\left(K_{p}\right.$ between $3^{+}$and $6, a m$ between 30 and 90). The high number of events with a positive $D_{s t}$ (right column on panel f) is based on a small number of plasmasphere passes with such $D_{s t}$ level (right column on panel c), and should therefore be interpreted with caution.

\subsection{Characteristics of the plasmaspheric plumes}

Let us study the typical properties of the plasmaspheric plumes in our database, as shown in Fig. 10. The plumes show all possible density variations (panel a) in the range accessible to WHISPER (up to $80 \mathrm{kHz}$ ), but with more events with small density variations $\left(<30 \mathrm{~cm}^{-3}\right)$. The plumes have no preferred maximum density value (see panel b). Logically, we have also more plume crossings with a short time duration (panel c); the characteristic time duration is $15 \mathrm{~min}$. Note that this characteristic time depends on the orbit of the Cluster satellites, on their speed, and on the latitude at which the plumes are crossed. A physically more useful characteristic is the width $\Delta L$ of the plume. It varies up to $6 R_{E}$ (panel d), with more events with a small $\Delta L(65 \%$ of the plumes have a width below $1.5 R_{E}$ ). The characteristic value of $\Delta L$ is $1.2 R_{E}$. 

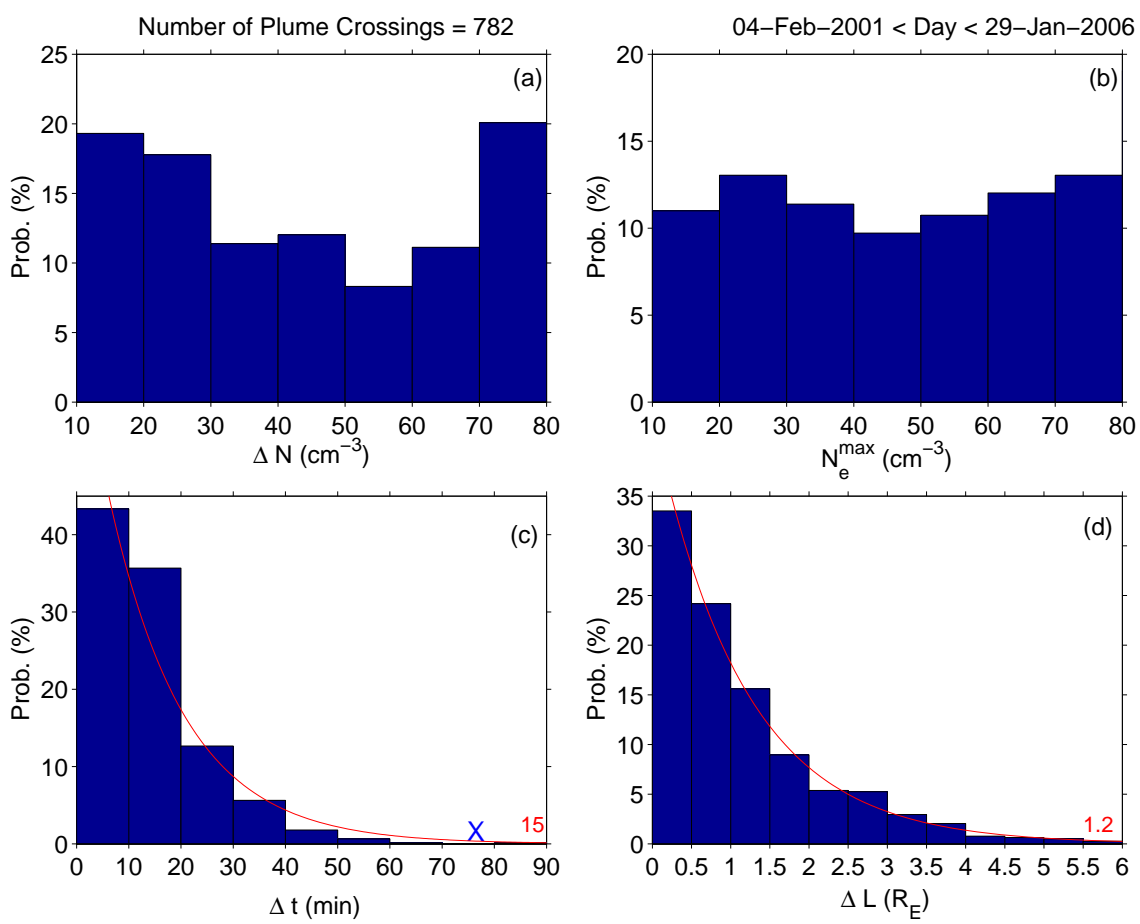

Fig. 10. Typical characteristics of the plasmaspheric plumes observed by WHISPER during the five years of Cluster data analysed. (a) Probability of the density variation $\Delta N$ inside the plumes. (b) Probability of the maximum density $N_{e}^{\max }$ inside the plumes. (c) Probability of the time duration $\Delta t$ of the plume crossings. (d) Probability of the width $\Delta L$ of the plumes. A blue cross means no data in this range. The red curves are exponential least-square fitting curves.

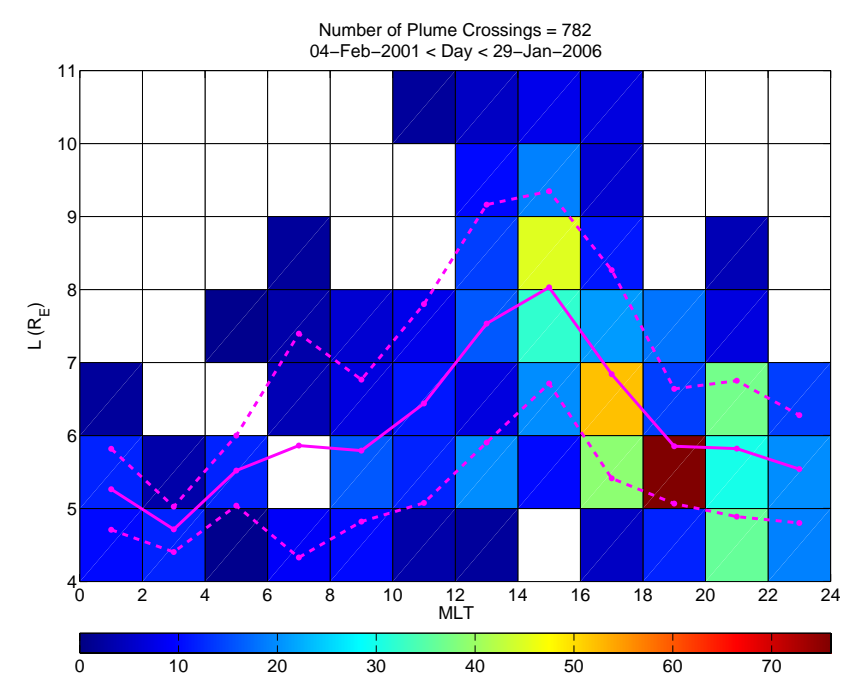

Fig. 11. Distribution of plasmaspheric plumes observed by WHISPER onboard Cluster during the five years of data analysed. The $L$ position of the plume is shown as a function of MLT. The color code gives the number of events in each bin. The solid magenta curve gives the mean $L$ value inside each MLT range, and the two dashed magenta curves the standard deviation of this value.

\subsection{Distribution of plasmaspheric plumes}

\subsubsection{Position $L$ as a function of MLT}

Each plume crossing has been analysed in terms of its $L$ position as a function of MLT. The results are shown in Fig. 11, where the color code gives the number of plume crossings in the $L-$ MLT bins. Plumes are observed especially in the afternoon MLT sector, for all $L$ values, while very few are observed in the overall morning MLT sector (the mean value of the number of events is around 2-3). This is due also to the fact that Cluster can observe only the tips of the plumes. Plumes at lower $L$ are seen in all MLT sectors, whereas plumes farther out are observed only in the afternoon MLT sector (10:00-18:00 MLT).

\subsubsection{Width $\Delta L$ as a function of MLT and $L$}

Each plume crossing has been analysed in terms of its width $\Delta L$ as a function of $L$ and MLT. The results are shown in Fig. 12, where the color code gives the number of plume crossings in the $\Delta L-$ MLT bins (top panel) and in the $\Delta L-L$ bins (bottom panel). The broadest plumes are observed in the afternoon MLT sector and at high $L$, while the narrowest ones are seen at small $L$ (below $7 R_{E}$ ) and in all MLT sectors, but mostly in the afternoon and pre-midnight MLT 

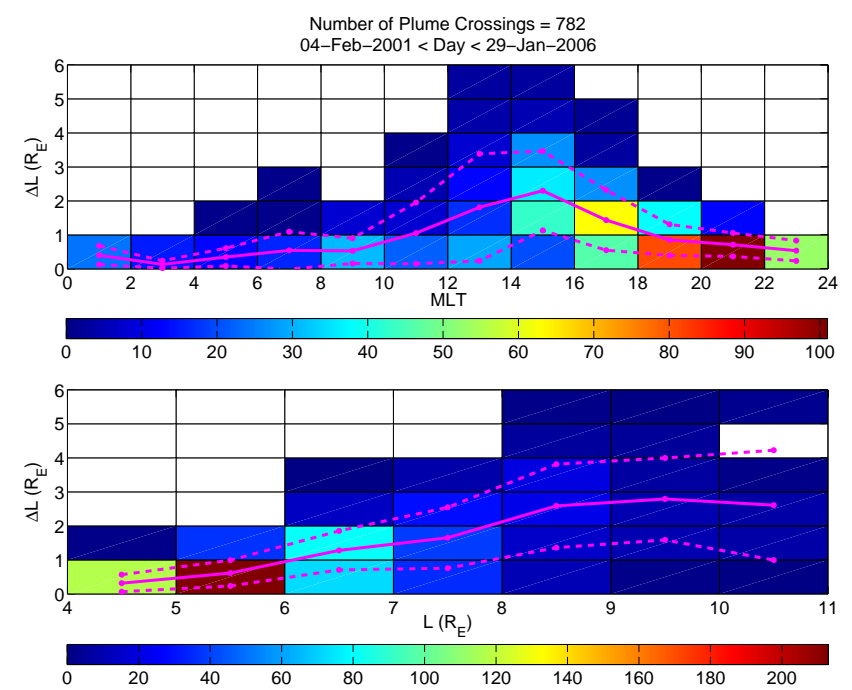

Fig. 12. Distribution of plasmaspheric plumes observed by WHISPER onboard Cluster during the five years of data analysed. The width $\Delta L$ of the plume is shown as a function of MLT in the top panel, and as a function of $L$ in the bottom panel. The color code gives the number of events in each bin. The solid magenta curves give the mean $\Delta L$ value inside each MLT range in the top panel, and inside each $L$ range in the bottom panel, and the two dashed magenta curves the standard deviations of those values.

sectors. Note that, by definition, no plumes with large $\Delta L$ are observed at small $L$.

\subsubsection{Density variation $\Delta N$ as a function of MLT and $L$}

Figure 13 presents the distribution of the density variation $\Delta N$ inside the plasmaspheric plumes, as a function of MLT (top panel) and $L$ (bottom panel). Globally, there are more plumes at lower and middle $L$ values $\left(5-8 R_{E}\right)$, and in the afternoon and pre-midnight MLT sectors (12:00-22:00 MLT). The less dense plumes are observed at all $L$ distances (but mostly at $L>7 R_{E}$ ), and mainly in the afternoon MLT sector (12:00-18:00 MLT). Denser plumes $\left(>40 \mathrm{~cm}^{-3}\right)$ are observed especially at small $L\left(5-7 R_{E}\right)$ and in all MLT sectors (except morning), mostly afternoon and pre-midnight MLT sectors (14:00-22:00 MLT).

\subsubsection{Density variation $\Delta N$ as a function of width $\Delta L$}

To have an idea of the structure of a plasmaspheric plume, it is important to study the density variation as a function of width. This is presented in Fig. 14. Most of the plumes are narrow $\left(\Delta L<1.5 R_{E}\right)$, but with all possible density variations (on the range available with WHISPER: $10-80 \mathrm{~cm}^{-3}$ ). There is no preferred density variation for the narrowest plumes. The plumes with small density variation can have all possible widths.
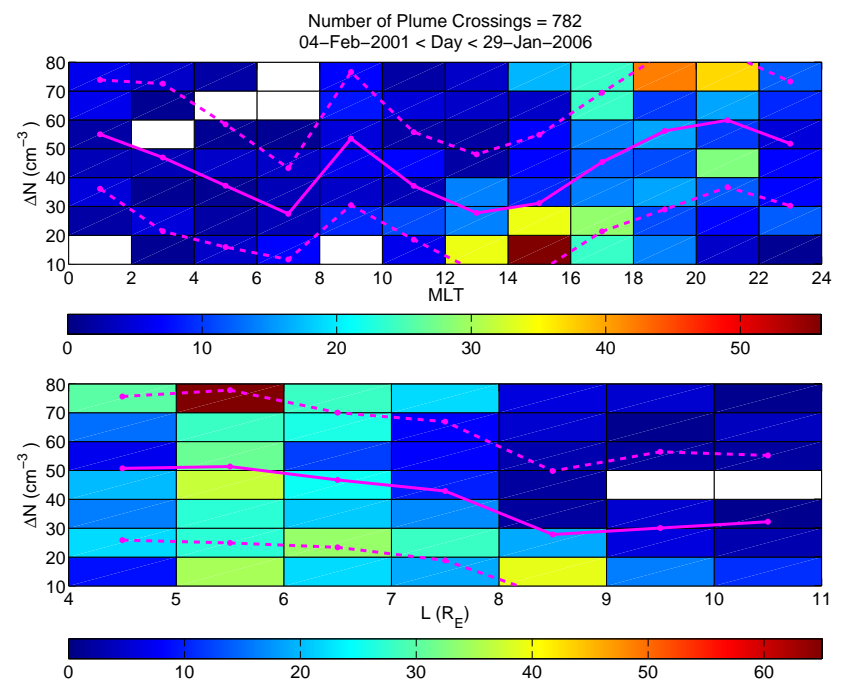

Fig. 13. Distribution of plasmaspheric plumes observed by WHISPER onboard Cluster during the five years of data analysed. The density variation $\Delta N$ is shown as a function of MLT in the top panel, and as a function of $L$ in the bottom panel. The color code gives the number of events in each bin. The solid magenta curves give the mean $\Delta N$ value inside each MLT range in the top panel, and inside each $L$ range in the bottom panel, and the two dashed magenta curves the standard deviations of those values.

3.5 Comparison between inbound and outbound crossings of the same plumes

As the Cluster satellites usually cross the same plume during subsequent inbound and outbound plasmasphere passes, it is interesting to make a comparison between such crossings. Such a comparison shows the transformation of a plume on a time scale of a few hours and the corresponding change in local time. We have restricted our study to a global comparison between all four satellites, and not one by one, to be sure that we are analysing the same plume. We have 212 events for this comparative study, as some plumes are sometimes seen only during the inbound or outbound crossing, or not by all four spacecraft. Figure 15 presents the apparent radial velocity $V_{\text {out-in }}^{\text {inner }}$ of the inner boundary of a plume crossed in both hemispheres. This velocity is plotted as a function of the average $L$ at which the inner plume boundary is observed in the inbound and outbound crossings. It is computed for all four satellites from the displacement in $L$ position of the boundary and from the time difference between both crossings, assuming that both crossings are observed approximately at the same MLT. The magenta curve gives a linear least-square fit of this apparent radial velocity. $V_{\text {out-in }}^{\text {inner }}$ ranges between -1.5 and $+1.5 \mathrm{~km} \mathrm{~s}^{-1}$. This is due to the large diversity in the plume database, with very different orbital configurations and plume structures. However, the values are mostly positive, which shows an apparent 


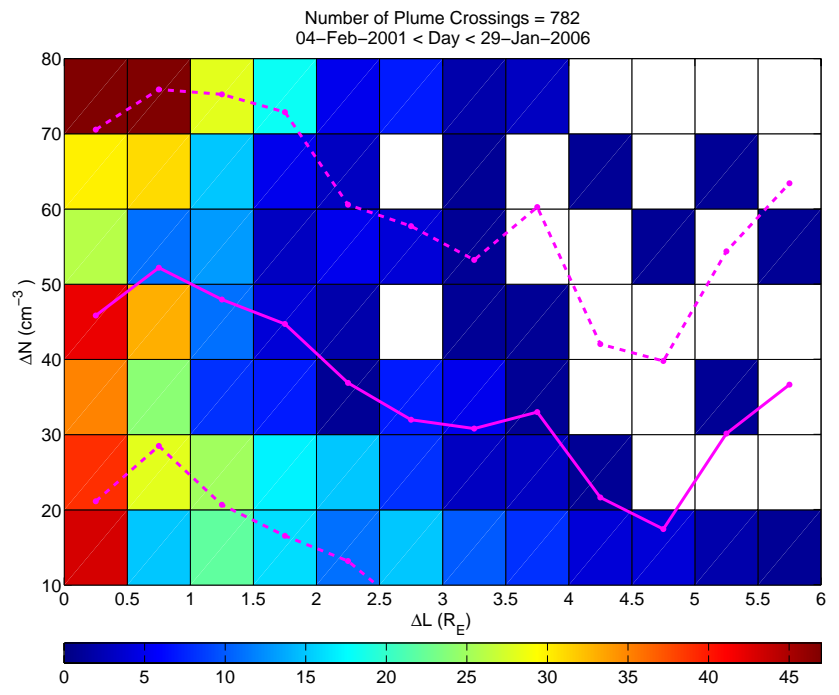

Fig. 14. Distribution of plasmaspheric plumes observed by WHISPER onboard Cluster during the five years of data analysed. The density variation $\Delta N$ is shown as a function of the width $\Delta L$. The color code gives the number of events in each bin. The solid magenta curve gives the mean $\Delta N$ value inside each $\Delta L$ range, and the two dashed magenta curves the standard deviation of this value.

outward motion of the plume towards higher $L$ values. The linear fit shows that the velocity is smaller for nearby plumes than for far-away plumes. The mean apparent radial velocity is around $0.25 \mathrm{~km} \mathrm{~s}^{-1}$, in agreement with a previous study by Darrouzet et al. (2006a). From this apparent radial velocity $V_{\text {out-in }}^{\text {inner }}$ and assuming full co-rotation of the plume at $V_{\text {out-in }}^{\text {corot }}$, we can compute an average winding angle $\alpha$ of the plume boundary with

$\sin (\alpha)=\frac{V_{\text {out-in }}^{\text {inner }}}{V_{\text {out-in }}^{\text {corot }}}$.

For an average position of the plume around $L=5.7 R_{E}$, and a corresponding co-rotation velocity of $2.6 \mathrm{~km} \mathrm{~s}^{-1}$, we find a typical winding angle of $5.5^{\circ}$ for the inner plume boundary, if we describe it as an Archimedean spiral.

\section{Conclusions}

A statistical analysis of plasmaspheric plumes has been done with five years of Cluster data, despite the fact that the orbit of Cluster is not optimal for a statistical study of this region due to its relatively high perigee, and despite the limitations of the WHISPER instrument (maximum electron density around $80 \mathrm{~cm}^{-3}$ ). In fact, our analysis is only able to detect plumes in the outer plasmasphere. Plumes seem to be a quite common feature observed in the outer region of the plasmasphere (15\% of the time). A small increase of geomagnetic activity is sufficient to produce plumes. They are

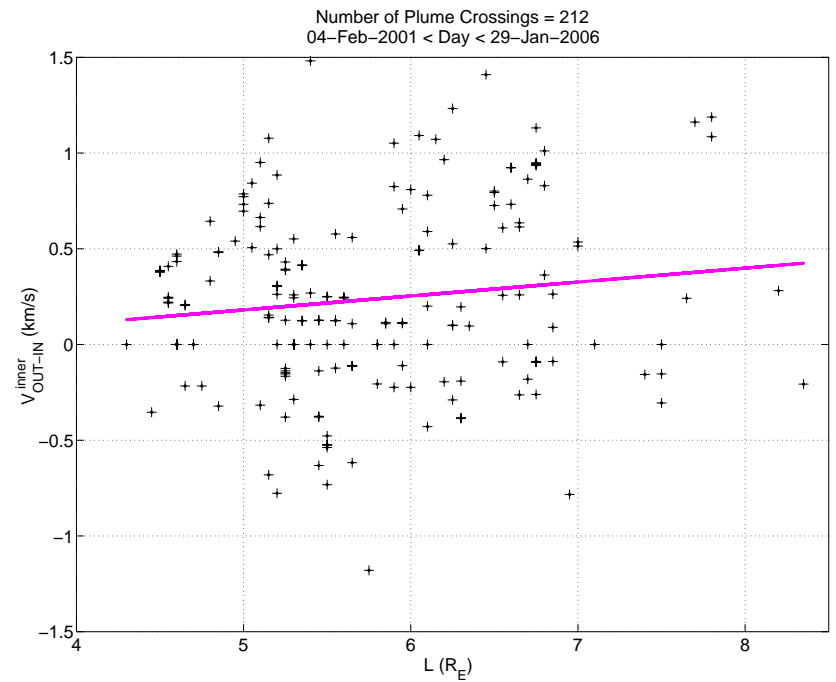

Fig. 15. Characteristics of the plumes observed by the same satellite in the inbound and outbound plasmasphere passes: apparent radial velocity $V_{\text {out-in }}^{\text {inner }}$ of the inner boundary of a plume crossed in both hemispheres. This velocity is plotted as a function of the average $L$ at which the inner plume boundary is observed in the inbound and outbound crossings. The magenta curve gives a linear least-square fit of this velocity.

observed mostly for moderate $K_{p}(3-6)$ and $a m(40-90)$ and not for smallest $D_{s t}$.

Plasmaspheric plumes are observed mainly in the afternoon and pre-midnight MLT sectors, and sometimes in the morning MLT sector. Denser plumes are observed especially at small $L$ (around 5-7 $R_{E}$ ) and in all MLT sectors (except morning), mostly pre-midnight. There is a large number of narrow plumes at small $L$ (below $7 R_{E}$ ) in all MLT sectors. Broad plumes, by definition occurring at large $L$ only, have low densities. Such results are in agreement with previous studies, especially with the CRRES study by Moldwin et al. (2004) concerning the $L$-MLT distribution and geomagnetic indices results. An early OGO 5 study also found that "detached plasma regions", now understood to be plumes, are mostly observed in the afternoon sector (Chappell, 1974).

The Cluster orbits allow to make a comparative study between an inbound plume crossing and the corresponding outbound one. Usually both crossings are separated by a few hours. From such comparisons between inbound and outbound crossings of the same plume seen by the same satellite, we conclude that during the plasmasphere pass, the plume has rotated and moved to higher $L$ values. The mean apparent radial velocity is around $0.25 \mathrm{~km} \mathrm{~s}^{-1}$. Imagining the inner boundary of a plume to have typically the form of an Archimedean spiral, we find a typical winding angle of $5.5^{\circ}$, although there is much case-to-case variation.

In the future, we plan to extend the statistical analysis with plasmasphere passes in 2006 and especially in 2007, because 
then the spacecraft separation distance is larger, which gives a more independent dataset. We would also like to study the influence of the IMF.

Acknowledgements. The IMF $Y$ and $Z$ components, and the $K_{p}$ and $D_{S t}$ indices were provided by the Space Environment Information System (SPENVIS) website (http://www.spenvis.oma.be). The am index was provided by the International Service of Geomagnetic Indices (ISGI) website (http://isgi.cetp.ipsl.fr/). The authors thank the referees for their thorough review of the manuscript and for their constructive suggestions. F. Darrouzet and J. De Keyser acknowledge the support by the Belgian Federal Science Policy Office (BELSPO) through the ESA/PRODEX-8 Cluster project (contract 13127/98/NL/VJ (IC)).

Topical Editor I. A. Daglis thanks J. L. Burch and M. Spasojević for their help in evaluating this paper.

\section{References}

Abe, S., Kawano, H., Goldstein, J., Ohtani, S., Solovyev, S. I., Baishev, D. G., and Yumoto, K.: Simultaneous identification of a plasmaspheric plume by a ground magnetometer pair and IMAGE Extreme Ultraviolet Imager, J. Geophys. Res., 111, A11202, doi:10.1029/2006JA011653, 2006.

Borovsky, J. E., Thomsen, M. F., McComas, D. J., Cayton, T. E., and Knipp, D. J.: Magnetospheric dynamics and mass flow during the November 1993 storm, J. Geophys. Res., 103, $26373-$ 26394, 1998.

Burch, J. L.: IMAGE mission overview, Space Sci. Rev., 91, 1-14, 2000.

Canu, P., Décréau, P. M. E., Trotignon, J. G., Rauch, J. L., Séran, H. C., Fergeau, P., Lévêque, M., Martin, P., Sené, F. X., Le Guirriec, E., Alleyne, H., and Yearby, K.: Identification of natural plasma emissions observed close to the plasmapause by the Cluster-Whisper relaxation sounder, Ann. Geophys., 19, 16971709, 2001, http://www.ann-geophys.net/19/1697/2001/.

Carpenter, D. L. and Anderson, R. R.: An ISEE/Whistler Model of Equatorial Electron Density in the Magnetosphere, J. Geophys. Res., 97, 1097-1108, 1992.

Carpenter, D. L. and Lemaire, J.: The Plasmasphere Boundary Layer, Ann. Geophys., 22, 4291-4298, 2004, http://www.ann-geophys.net/22/4291/2004/.

Carpenter, D. L., Smith, A. J., Giles, B. L., Chappell, C. R., and Décréau, P. M. E.: A Case Study of Plasma Structure in the Dusk Sector Associated with Enhanced Magnetospheric Convection, J. Geophys. Res., 97, 1157-1166, 1992.

Carpenter, D. L., Giles, B. L., Chappell, C. R., Décréau, P. M. E., Anderson, R. R., Persoon, A. M., Smith, A. J., Corcuff, Y., and Canu, P.: Plasmasphere Dynamics in the Duskside Bulge Region: A New Look at an Old Topic, J. Geophys. Res., 98, 19243-19271, 1993.

Chappell, C. R.: Detached Plasma Regions in the Magnetosphere, J. Geophys. Res., 79, 1861-1870, 1974.

Chappell, C. R., Harris, K. K., and Sharp, G. W.: A Study of the Influence of Magnetic Activity on the Location of the Plasmapause as Measured by OGO 5, J. Geophys. Res., 75, 50-56, 1970a.
Chappell, C. R., Harris, K. K., and Sharp, G. W.: The Morphology of the Bulge Region of the Plasmasphere, J. Geophys. Res., 75, 3848-3861, 1970b.

Chen, A. J. and Grebowsky, J. M.: Plasma Tail Interpretations of Pronounced Detached Plasma Regions Measured by Ogo 5, J. Geophys. Res., 79, 3851-3855, 1974.

Chen, A. J. and Wolf, R. A.: Effects on the plasmasphere of a timevarying convection electric field, Planet. Space Sci., 20, 483509, 1972.

Dandouras, I., Pierrard, V., Goldstein, J., Vallat, C., Parks, G. K., Rème, H., Gouillart, C., Sevestre, F., McCarthy, M., Kistler, L. M., Klecker, B., Korth, A., Bavassano-Cattaneo, M. B., Escoubet, P., and Masson, A.: Multipoint Observations of Ionic Structures in the Plasmasphere by CLUSTER-CIS and Comparisons With IMAGE-EUV Observations and With Model Simulations, in: Inner Magnetosphere Interactions: New Perspectives from Imaging, edited by: Burch, J., Schulz, M., and Spence, H., no. 159 in Geophysical Monograph Series, pp. 23-53, American Geophysical Union, Washington, 2005.

Darrouzet, F., Décréau, P. M. E., De Keyser, J., Masson, A., Gallagher, D. L., Santolík, O., Sandel, B. R., Trotignon, J. G., Rauch, J. L., Le Guirriec, E., Canu, P., Sedgemore, F., André, M., and Lemaire, J. F.: Density structures inside the plasmasphere: Cluster observations, Ann. Geophys., 22, 2577-2585, 2004, http://www.ann-geophys.net/22/2577/2004/.

Darrouzet, F., De Keyser, J., Décréau, P. M. E., Gallagher, D. L., Pierrard, V., Lemaire, J. F., Sandel, B. R., Dandouras, I., Matsui, H., Dunlop, M., Cabrera, J., Masson, A., Canu, P., Trotignon, J. G., Rauch, J. L., and André, M.: Analysis of plasmaspheric plumes: CLUSTER and IMAGE observations, Ann. Geophys., 24, 1737-1758, 2006a, http://www.ann-geophys.net/24/1737/2006/.

Darrouzet, F., De Keyser, J., Décréau, P. M. E., Lemaire, J. F., and Dunlop, M. W.: Spatial gradients in the plasmasphere from Cluster, Geophys. Res. Lett., 33, L08105, doi:10.1029/ 2006GL025727, 2006b.

De Keyser, J., Darrouzet, F., Dunlop, M. W., and Décréau, P. M. E.: Least-squares gradient calculation from multi-point observations of scalar and vector fields: Methodology and applications with Cluster in the plasmasphere, Ann. Geophys., 25, 971-987, 2007, http://www.ann-geophys.net/25/971/2007/.

Décréau, P. M. E., Fergeau, P., Krasnosels'kikh, V., Lévêque, M., Martin, P., Randriamboarison, O., Sené, F. X., Trotignon, J. G., Canu, P., Mögensen, P. B., and Whisper Investigators: WHISPER, A Resonance Sounder and Wave Analyser: Performances and Perspectives for the Cluster Mission, Space Sci. Rev., 79, 157-193, 1997.

Décréau, P. M. E., Fergeau, P., Krasnosels'kikh, V., Le Guirriec, E., Lévêque, M., Martin, P., Randriamboarison, O., Rauch, J. L., Sené, F. X., Séran, H. C., Trotignon, J. G., Canu, P., Cornilleau, N., de Féraudy, H., Alleyne, H., Yearby, K., Mögensen, P. B., Gustafsson, G., André, M., Gurnett, D. A., Darrouzet, F., Lemaire, J., Harvey, C. C., Travnicek, P., and Whisper experimenters: Early results from the Whisper instrument on Cluster: an overview, Ann. Geophys., 19, 1241-1258, 2001, http://www.ann-geophys.net/19/1241/2001/.

Décréau, P. M. E., Ducoin, C., Le Rouzic, G., Randriamboarison, O., Rauch, J. L., Trotignon, J. G., Vallières, X., Canu, P., Darrouzet, F., Gough, M. P., Buckley, A., and Carozzi, T. D.: Obser- 
vation of Continuum radiations from the CLUSTER fleet: first results from direction finding, Ann. Geophys., 22, 2607-2624, 2004 , http://www.ann-geophys.net/22/2607/2004/.

Décréau, P. M. E., Le Guirriec, E., Rauch, J. L., Trotignon, J. G., Canu, P., Darrouzet, F., Lemaire, J., Masson, A., Sedgemore, F., and André, M.: Density irregularities in the plasmasphere boundary player: Cluster observations in the dusk sector, Adv. Space Res., 36, 1964-1969, 2005.

El-Lemdani Mazouz, F., Grimald, S., Rauch, J. L., Décréau, P. M. E., Bozan, G., Le Rouzic, G., Suraud, X., Vallières, X., Trotignon, J. G., Canu, P., Darrouzet, F., and Boardsen, S.: Electrostatic and electromagnetic emissions near the plasmasphere. A case event: 27 May 2003, Proceedings of the Cluster and Double Star Symposium, 5th Anniversary of Cluster in Space, ESA SP-598, 2006.

El-Lemdani Mazouz, F., Rauch, J. L., Décréau, P. M. E., Trotignon, J. G., Vallières, X., Darrouzet, F., Canu, P., and Suraud, X.: Wave emissions at half electron gyroharmonics in the equatorial plasmasphere region: CLUSTER observations and statistics, Adv. Space Res., in press, doi:10.1016/j.asr.2008.06.007, 2008.

Elphic, R. C., Weiss, L. A., Thomsen, M. F., McComas, D. J., and Moldwin, M. B.: Evolution of plasmaspheric ions at geosynchronous orbit during times of high geomagnetic activity, Geophys. Res. Lett., 23, 2189-2192, 1996.

Escoubet, C. P., Russell, C. T., and Schmidt, R. (Eds.): The Cluster and Phoenix Missions, Kluwer Academic Publishers, Dordrecht, 1997.

Foster, J. C., Erickson, P. J., Coster, A. J., Goldstein, J., and Rich, F. J.: Ionospheric signatures of plasmaspheric tails, Geophys. Res. Lett., 29, 1623, doi:10.1029/2002GL015067, 2002.

Garcia, L. N., Fung, S. F., Green, J. L., Boardsen, S. A., Sandel, B. R., and Reinisch, B. W.: Observations of the latitudinal structure of plasmaspheric convection plumes by IMAGE-RPI and EUV, J. Geophys. Res., 108, 1321, doi:10.1029/2002JA009496, 2003.

Goldstein, J. and Sandel, B. R.: The Global Pattern of Evolution of Plasmaspheric Drainage Plumes, in: Inner Magnetosphere Interactions: New Perspectives from Imaging, edited by Burch, J. L., Schulz, M., and Spence, H., no. 159 in Geophysical Monograph Series, pp. 1-22, American Geophysical Union, Washington, 2005.

Goldstein, J., Sandel, B. R., Hairston, M. R., and Reiff, P. H.: Control of plasmaspheric dynamics by both convection and subauroral polarization stream, Geophys. Res. Lett., 30, 2243, doi: 10.1029/2003GL018390, 2003a.

Goldstein, J., Spasojević, M., Reiff, P. H., Sandel, B. R., Forrester, W. T., Gallagher, D. L., and Reinisch, B. W.: Identifying the plasmapause in IMAGE EUV data using IMAGE RPI in situ steep density gradients, J. Geophys. Res., 108, 1147, doi: 10.1029/2002JA009475, 2003b.

Goldstein, J., Sandel, B. R., Thomsen, M. F., Spasojević, M., and Reiff, P. H.: Simultaneous remote sensing and in situ observations of plasmaspheric drainage plumes, J. Geophys. Res., 109, A03202, doi:10.1029/2003JA010281, 2004.

Grebowsky, J. M.: Model Study of Plasmapause Motion, J. Geophys. Res., 75, 4329-4333, 1970.

Kim, K.-H., Goldstein, J., and Berube, D.: Plasmaspheric drainage plume observed by the Polar satellite in the prenoon sector and the IMAGE satellite during the magnetic storm of 11 April 2001, J. Geophys. Res., 112, A06237, doi:10.1029/2006JA012030, 2007.

Kowalkowski, L. and Lemaire, J.: Contribution à l'étude des éléments de plasma détachés dans la magnétosphère, Bulletin de la Classe des Sciences, Académie Royale de Belgique, 65, 159173, 1979.

Lambour, R. L., Weiss, L. A., Elphic, R. C., and Thomsen, M. F.: Global modeling of the plasmasphere following storm sudden commencements, J. Geophys. Res., 102, 24 351-24 368, 1997.

Lemaire, J. F.: The mechanisms of formation of the plasmapause, Ann. Geophys., 31, 175-190, 1975, http://www.ann-geophys.net/31/175/1975/.

Lemaire, J. F.: The formation plasmaspheric tails, Phys. Chem. Earth (C), 25, 9-17, 2000.

Lemaire, J. F.: The formation of the light-ion-trough and peeling off the plasmasphere, J. Atmos. Solar-Terr. Phys., 63, 1285-1291, 2001.

Lemaire, J. F. and Gringauz, K. I. (Eds.): The Earth's Plasmasphere, Cambridge University Press, New York, 1998.

McIlwain, C. E.: Coordinates for Mapping the Distribution of Magnetically Trapped Particles, J. Geophys. Res., 66, 3681-3691, 1961.

Moldwin, M. B., Thomsen, M. F., Bame, S. J., McComas, D. J., and Moore, K. R.: An Examination of the Structure and Dynamics of the Outer Plasmasphere Using Multiple Geosynchronous Satellites, J. Geophys. Res., 99, 11 475-11 481, 1994.

Moldwin, M. B., Thomsen, M. F., Bame, S. J., McComas, D., and Reeves, G. D.: The Fine-Scale Structure of the Outer Plasmasphere, J. Geophys. Res., 100, 8021-8029, 1995.

Moldwin, M. B., Howard, J., Sanny, J., Bocchicchio, J. D., Rassoul, H. K., and Anderson, R. R.: Plasmaspheric plumes: CRRES observations of enhanced density beyond the plasmapause, J. Geophys. Res., 109, A05202, doi:10.1029/2003JA010320, 2004.

Ober, D. M., Horwitz, J. L., Thomsen, M. F., Elphic, R. C., McComas, D. J., Belian, R. D., and Moldwin, M. B.: Premidnight plasmaspheric "plumes", J. Geophys. Res., 102, 11 325-11334, 1997.

Pierrard, V. and Cabrera, J.: Comparisons between EUV/IMAGE observations and numerical simulations of the plasmapause formation, Ann. Geophys., 23, 2635-2646, 2005, http://www.ann-geophys.net/23/2635/2005/.

Pierrard, V. and Lemaire, J. F.: Development of shoulders and plumes in the frame of the interchange instability mechanism for plasmapause formation, Geophys. Res. Lett., 31, L05809, doi: 10.1029/2003GL018919, 2004.

Rème, H., Aoustin, C., Bosqued, J. M., Dandouras, I., Lavraud, B., Sauvaud, J. A., Barthe, A., Bouyssou, J., Camus, T., Coeur-Joly, O., Cros, A., Cuvilo, J., Ducay, F., Garbarowitz, Y., Médale, J. L., Penou, E., Perrier, H., Romefort, D., Rouzaud, J., Vallat, C., Alcaydé, D., Jacquey, C., Mazelle, C., d'Uston, C., Möbius, E., Kistler, L. M., Crocker, K., Granoff, M., Mouikis, C., Popecki, M., Vosbury, M., Klecker, B., Hovestadt, D., Kucharek, H., Kuenneth, E., Paschmann, G., Scholer, M., Sckopke, N., Seidenschwang, E., Carlson, C. W., Curtis, D. W., Ingraham, C., Lin, R. P., McFadden, J. P., Parks, G. K., Phan, T., Formisano, V., Amata, E., Bavassano-Cattaneo, M. B., Baldetti, P., Bruno, R., Chionchio, G., Di Lellis, A., Marcucci, M. F., Pallocchia, G., Korth, A., Daly, P. W., Graeve, B., Rosenbauer, H., Va- 
syliunas, V., McCarthy, M., Wilber, M., Eliasson, L., Lundin, R., Olsen, S., Shelley, E. G., Fuselier, S., Ghielmetti, A. G., Lennartsson, W., Escoubet, C. P., Balsiger, H., Friedel, R., Cao, J.-B., Kovrazhkin, R. A., Papamastorakis, I., Pellat, R., Scudder, J., and Sonnerup, B.: First multi-spacecraft ion measurements in and near the Earth's magnetosphere with the identical Cluster ion spectrometry (CIS) experiment, Ann. Geophys., 19, 1303-1354, 2001 , http://www.ann-geophys.net/19/1303/2001/.

Sandel, B. R., Broadfoot, A. L., Curtis, C. C., King, R. A., Stone, T. C., Hill, R. H., Chen, J., Siegmund, O. H. W., Raffanti, R., Allred, D. D., Turley, R. S., and Gallagher, D. L.: The extreme ultraviolet imager investigation for the IMAGE mission, Space Sci. Rev., 91, 197-242, 2000.

Sandel, B. R., Goldstein, J., Gallagher, D. L., and Spasojević, M.: Extreme ultraviolet imager observations of the structure and dynamics of the plasmasphere, Space Sci. Rev., 109, 25-46, 2003.

Spasojević, M., Goldstein, J., Carpenter, D. L., Inan, U. S., Sandel, B. R., Moldwin, M. B., and Reinisch, B. W.: Global response of the plasmasphere to a geomagnetic disturbance, J. Geophys. Res., 108, 1340, doi:10.1029/2003JA009987, 2003.

Spasojević, M., Frey, H. U., Thomsen, M. F., Fuselier, S. A., Gary, S. P., Sandel, B. R., and Inan, U. S.: The link between a detached subauroral proton arc and a plasmaspheric plume, Geophys. Res. Lett., 31, L04803, doi:10.1029/2003GL018389, 2004.

Spiro, R. W., Harel, M., Wolf, R. A., and Reiff, P. H.: Quantitative Simulation of a Magnetospheric Substorm, 3. Plasmaspheric Electric Fields and Evolution of the Plasmapause, J. Geophys. Res., 86, 2261-2272, 1981.
Su, Y., Thomsen, M. F., Borovsky, J. E., and Foster, J. C.: A linkage between polar patches and plasmaspheric drainage plumes, Geophys. Res. Lett., 28, 111-113, doi:10.1029/2000GL012042, 2001.

Taylor, H. A. J., Grebowsky, J. M., and Walsh, W. J.: Structured Variations of the Plasmapause: Evidence of a Corotating Plasma Tail, J. Geophys. Res., 76, 6806-6814, 1971.

Trotignon, J. G., Décréau, P. M. E., Rauch, J. L., Randriamboarison, O., Krasnosels'kikh, V., Canu, P., Alleyne, H., Yearby, K., Le Guirriec, E., Séran, H. C., Sené, F. X., Martin, P., Lévêque, M., and Fergeau, P.: How to determine the thermal electron density and the magnetic field strength from the CLUSTER/WHISPER observations around the Earth, Ann. Geophys., 19, 1711-1720, 2001, http://www.ann-geophys.net/19/1711/2001/.

Trotignon, J. G., Décréau, P. M. E., Rauch, J. L., Le Guirriec, E., Canu, P., and Darrouzet, F.: The Whisper Relaxation Sounder Onboard Cluster: A Powerful Tool for Space Plasma Diagnosis around the Earth, Cosmic Res., 41, 369-372, 2003.

Tsyganenko, N. A. and Stern, D. P.: Modeling the global magnetic field of the large-scale Birkeland current systems, J. Geophys. Res., 101, 27 187-27 198, 1996.

Weiss, L. A., Lambour, R. L., Elphic, R. C., and Thomsen, M. F.: Study of plasmaspheric evolution using geosynchronous observations and global modeling, Geophys. Res. Lett., 24, 599-602, 1997.

Yizengaw, E., Moldwin, M. B., and Galvan, D. A.: Ionospheric signatures of a plasmaspheric plume over Europe, Geophys. Res. Lett., 33, L17103, doi:10.1029/2006GL026597, 2006. 